Témoigner Témoigner. Entre histoire et mémoire

Getuigen Revue pluridisciplinaire de la Fondation Auschwitz

118 | 2014

Au nom des victimes. Dictature et terreur d'État en Argentine, Chili et Uruguay

\title{
Herinneringslabo België-Belgique
}

In het volgende nummer

Laboratoire mémoriel Belgique-België

Memory laboratory Belgium-Belgique

\section{OpenEdition}

1 Journals

\section{Édition électronique}

URL : http://journals.openedition.org/temoigner/1143

DOI : 10.4000/temoigner.1143

ISSN : 2506-6390

Éditeur :

Éditions du Centre d'études et de documentation Mémoire d'Auschwitz, Éditions Kimé

\section{Édition imprimée}

Date de publication : 1 octobre 2014

Pagination : 210

ISBN : 978-2-84174-674-3

ISSN : 2031-4183

Référence électronique

"Herinneringslabo België-Belgique », Témoigner. Entre histoire et mémoire [En ligne], 118| 2014, mis en

ligne le 01 octobre 2015, consulté le 23 octobre 2020. URL : http://journals.openedition.org/

temoigner/1143; DOI : https://doi.org/10.4000/temoigner.1143 


\section{Rwanda}

\section{DE KERKEN-MASSAGRAVEN VAN DE GENOCIDE : KIBEHO}

$\diamond$ Door Rémi

Korman, EHESS

(École des Hautes

Etudes en Sciences
Sociales). Korman

reist regelmatig naar

Rwanda voor zijn

onderzoek naar de

genocide van de Tutsi's

en het herinneringswer

daarrond. Samen met

de vereniging lbuka in

Lyon zet hij eveneens

projecten op om

die herinnering

$\diamond$ Deze terugkerende

rubriek moet

inzicht verschaffen

in de processen

van herinnerings-

1994. Daarbij wordt

met de specifieke

kenmerken van het

herinneringsmodel

in Rwanda, maar er

is ook aandacht voor

verbanden met studies

over de Shoah, de

Armeense genocid

of de genocide in

Cambodja.

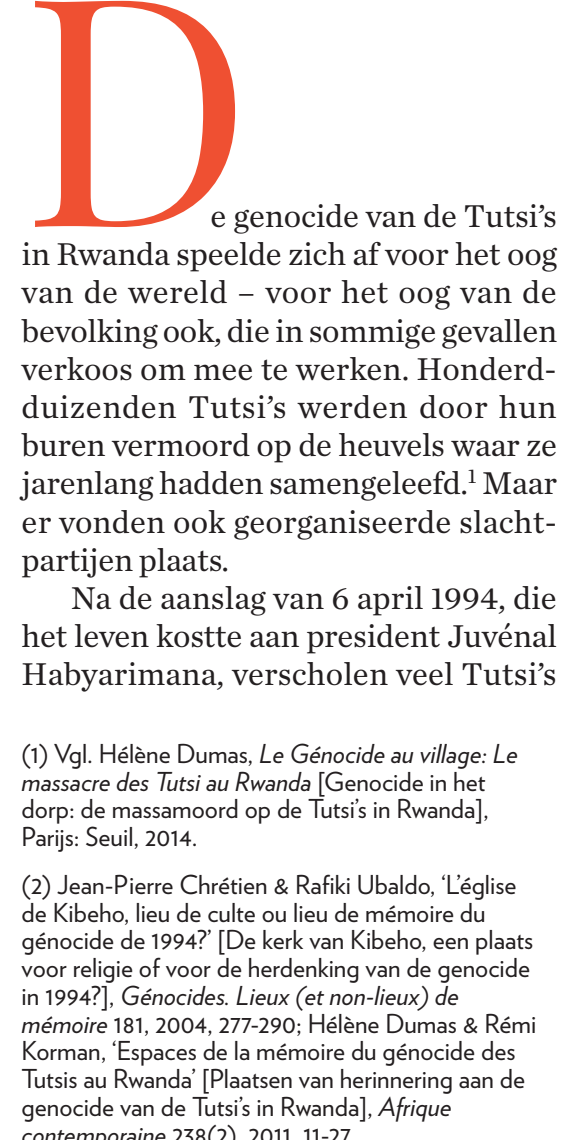

zich op publieke plaatsen. Soms deden ze zot zering. echoch chelon, nation aren de kerken altijd een toevlus ward geweest voor bed to oord geweest voor bedreigde Tutsi's. iijer talijke katholieke to is

Hoe is het zo ver kunnen komen dat het meest christelijke land va religieuze waarden ven norele en Maar bovent, wat is er van dez sites cour bovena, wat is er van deze sites geworden na de genocide? Zijn de religieuze bijenten nog? pleknogen mis opedrag Kan op zo' pleknogeen is wijdere wijden en 'zuivern' zodat ofom ze te 'zuiveren' zodater weer ere Om dat uit te maken, wor Om dat uit te maken, werd in 1996 verterenwordigers van de Katholieke Kerk en de Rwand va de Kat ${ }^{2}$ S liek Kerk en de Rwandse staat. Samen zochten ze naar een akkoord dat voor boide partijen aanvaardbaar zou zijn. 


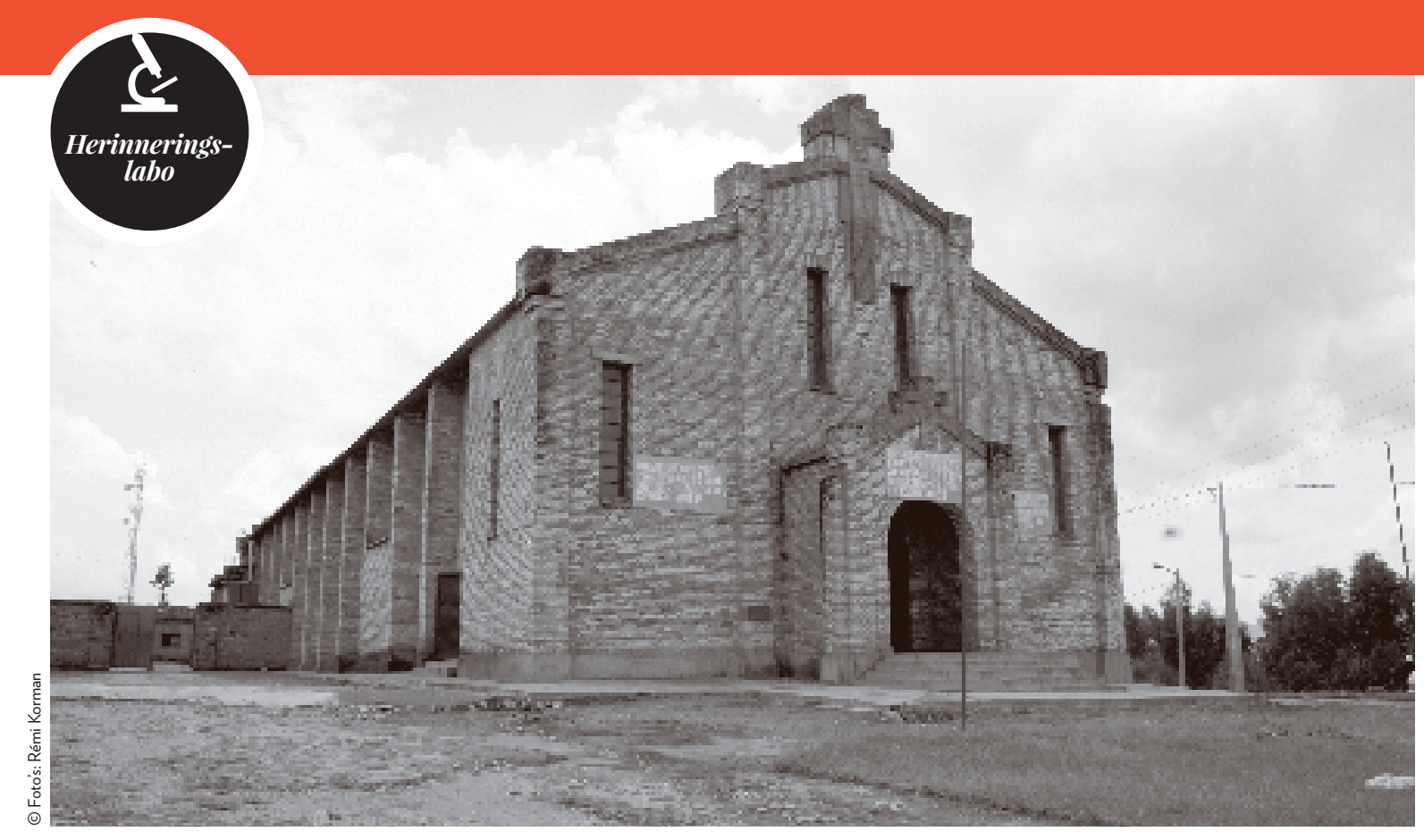

- Kerk van Kibeho
27 maart 2014.

•. der constructief toonde en bereid was om toegevingen te doen, sprak het Vaticaan zijn veto uit. De kerken mochten ingerie en Nya discuss Ntarda in de rego van Nyamata en Ntanara in de rego  plaatsen. Over cen bepalde site raakKibeho.

DE VERSCHIJNING VAN MARIA EN DE SLACHTPARTIJ IN DE PAROCHIE Kibeho ligt in het zuiden van Rwanda, in het huidige district Nyaruvan Gikongoro bevond. Tussen 28 november 1981 en 28 novenber 1989 ( amper een jaar voor het uitbreken van debura keren verscherio zaren le

Net als op zoveel andere plaatsen in Rwanda, dachten duizenden Tutsis chie. Op 14 april 1994 zetten soldaten en

milities onder leiding van onderprefect Damien Biniga echter de aanval in. Ze bliezen de ma echter de anvalin. Ze cran de site das het gebou in b. Uiteindelijkstakenze het gebouw in brand, zodat niet alleen .

\section{EEN VEELHEID AAN}

\section{HERINNERINGEN OP DE SITE}

VAN KIBEHO

De Rwandese regering en een aantal verenigingen van overlevenden ijverden na de genocide voor de omvorming bisde bisdom en de bisschoppenconferentie waren daar fel tegengekant. De regering Tijidens de vijfde van de cenocide op 7 april 1999 , beschulpublickelijk Mgr Misamo, de bisung publiekelijk Mgr. Misago, de bisschop van Gikongoro, van deelname aan de Mariaverschijningen in Rwanda

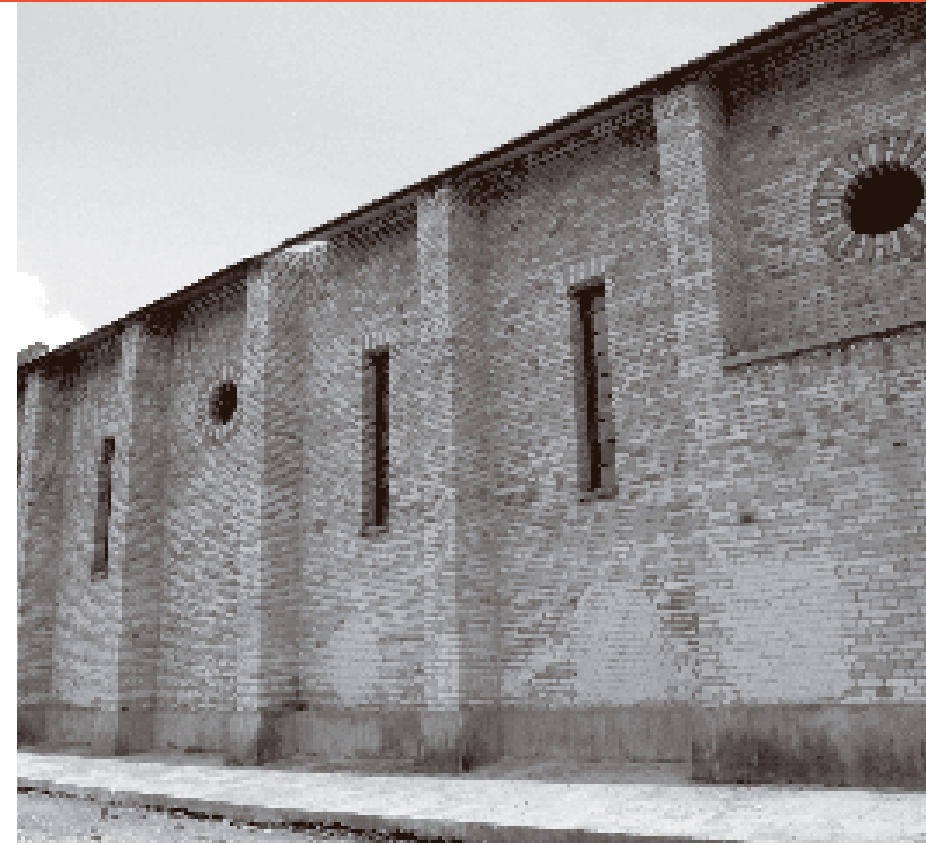

-Rechtse zijmuur van de kerk
De plaatsen waarlangs de

moordenaars binnenkwamen
zijn in het grijs geschilderd.

- Binnen in de kerk van

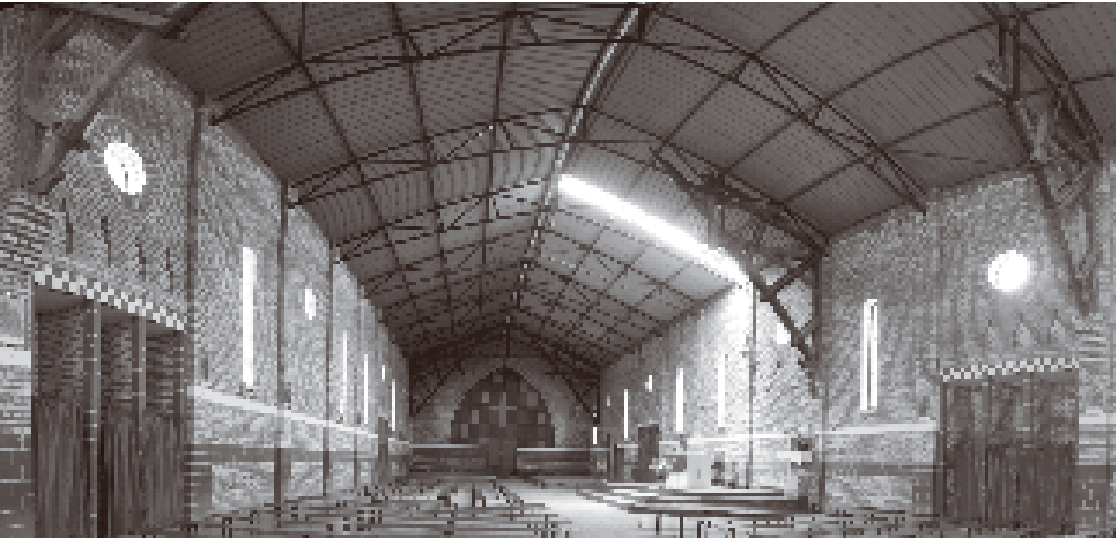
dicher digde recideop aprill Katholieke Kenngu verklaarde: als de de stenen en de ramen kwijt is waarmee deze kerk is gebouwd, omdat de Rwandese staat er een memoriaal van wil maken, dat ze het dan zegt, dan zetten we gewoon een ander gebouw'.

Een week later werd Mgr. Misago angehouden. De reactie van de Kerk liet niet lang op zich wachten: het Vaticaan publiceerde negationistische teksten in L'Osservatore Romano en uitte felle kntickop de resering in Kigali. Het openbare proces dat erop volgde, ko binnel wat belanstenthy rekenen in bijar rijspraak, op 15juni2001, enkende Mgr. vis

$\mathrm{Na}$ een rustigere periode kwam men in 2003 tot een compromis ove chench word word Dat be datook de herdening - letterlijk - een belang ine plats kreg. In een aparte memori det meffelijke ov nu een dat ook de site bewand bleef, maar ten. De herinnering aan de genocide werd bovendien gematerialiseerd door de inscriptie an deingangan hetgebow Denzen die in 1994 door grebouw. Denuren brijzeld en warlangs de wor werde kerk binnenkwamen, woordenaars (on center Katholieke Kerk. In 2013 besliste de Rwandese regeringom demuren in het gijs te overschlderen, de mate kleur van de rou Tot st werd cen de rerk den mem. Tot ouwd war licam achtoffers uitgestald liggen

De kwestie van Kibeho illustreert Katholieke Kerk en de Rwandese regering in de periode na de genocide. bandaag is de kerk een heiligdom waar bezoekers uit binnen- en buitenland toestromen. De Rwandese staat ziet de cite als oncilie symbol st tweede vaticaans het herinneringsconflict tussen de een belangijk cor

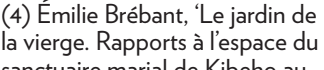
Rwanda' 'De tuin van de maagd.

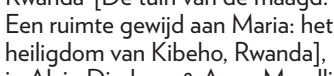
Topographie dus \& Anne Morel Topographie du sacre. Lemprise
religieuse sur l' espace, Brussel. 


\section{IN HET VOLGENDE NUMMER Herinneringslabo België-Belgique}

I n deze rubriek leggen we de focus op herinnering in een Belgische context. Er zullen bijdragen verschijnen van onderzoekers uit België en het buitenland, actief in verschillende disciplines. Verwacht u aan interviews, synthesen van onderzoeksprojecten, boekrecensies, aankondigingen van theatervoorstellingen en tentoonstellingen, dialogen en debatten. Het is de bedoeling om de actualiteit van nabij te volgen en met name de herdenking van 100 jaar Eerste Wereldoorlog. Die oorlog heeft immers een opmerkelijke impact gehad op de nationale en regionale identiteiten in België.

Vijf onderzoekers, zowel Nederlands- als Franstalig, zullen de inhoud van deze rubriek verzorgen. Hoewel ze onderzoek voeren in verschillende domeinen van de sociale en menswetenschappen, werken ze sinds een aantal jaren nauw samen rond collectieve herinnering en Belgische identiteiten. I

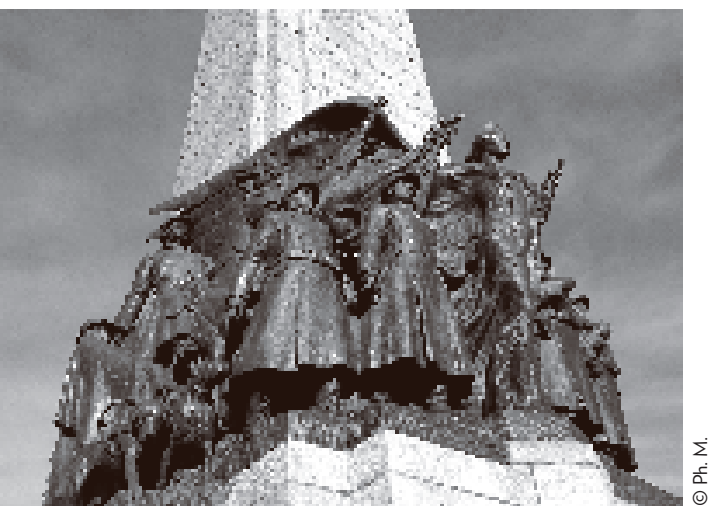

De veelvormige verbeelding van het verleden staat centraal in het onderzoek van Marnix Beyen, dat zich richt op de negentiende- en twintigsteeeuwse geschiedenis van België en Nederland. Daarbij besteedt hij vooral aandacht aan de constructie van politieke identiteiten via gedeelde master narratives over het verleden en via commemoratieve praktijken en objecten (historische romans, herdenkingen, straatnamen...) waarin die verhalen vorm krijgen.

Elke Brems is coördinator van het Centre for Reception Studies van de KULeuven Campus Brussel. Ze doet onderzoek op het snijvlak van literatuur- en vertaalwetenschap. Meer bepaald bestudeert ze aspecten van culturele transfer: het circuleren van literatuur en cultuur via receptie, vertaling, adaptatie. Meestal staat de Nederlandse literatuur uit de eerste helft van de twintigste eeuw en haar relatie tot andere literaturen daarbij centraal.

Olivier Luminet is professor psychologie (UCL en ULB) en onderzoeker bij het FRS-FNRS. Hij bestudeert de verbanden tussen emotie, identiteit en individuele of collectieve herinnering. Recent spitste zijn onderzoek zich toe op de Belgische geschiedenis: de Leuvense kwestie, maar ook de intergenerationele herinneringen aan de Tweede Wereldoorlog. Zo redigeerde hij de bundel België-Belgique. Eén staat, twee collectieve geheugens? (2012), die verscheen in een Franstalige en een Nederlandstalige versie.

Laurence van Ypersele is professor aan de UCL, waar ze hedendaagse geschiedenis doceert. Ze is auteur en medeauteur van een reeks werken over de Eerste Wereldoorlog. We onthouden De la guerre de l'ombre aux ombres de la guerre [Een oorlog in de schaduw, de schaduw van de oorlog] (Labor, 2004), Le roi Albert, histoire d'un mythe [Koning Albert, geschiedenis van een mythe] (Labor, 2006), La Patrie crie vengeance [Het vaderland schreeuwt om wraak] (Le Cri, 2008), Je serai fusillé demain [Morgen word ik gefusilleerd] (Racine, 2011) en Bruxelles, la mémoire et la guerre [Brussel, oorlog en herinnering] (La Renaissance du Livre, 2014).

Geneviève Warland (UCL) is historica en filosofe, gespecialiseerd in geschiedschrijving en theorie van de geschiedenis over de negentiende en twintigste eeuw. Ze voert onderzoek naar de manieren waarop de geschiedenis in de publieke ruimte wordt gebruikt om nationale identiteiten te creëren (in Duitsland, België, Frankrijk en Nederland). Daarnaast brengt ze de netwerken van historici over de grenzen heen in kaart. Momenteel gaat haar aandacht uit naar de Eerste Wereldoorlog, en meer bepaald naar de rol van de historicus-getuige. 